\title{
NOTA SOBRE OCORRÊNCIAS E SIGNIFICADOS DE SAECULUM EM AGOSTINHO
}

\author{
Note on Occurrences and Meanings of Saeculum in Augustine
}

Luiz Marcos da Silva Filho ${ }^{1}$

RESUMO: Nesta nota técnica, eu analiso os significados, ambiguidades e equivocidades de saeculum em Confissões, XI, e A cidade de Deus, XIII, i; XV, i e XXI, para entender melhor as concepções agostinianas de "eternidade", "tempo", "história universal", "tempo cósmico", "tempo histórico" e "mundo".

PALAVRAS-CHAVE: Saeculum; Eternidade; Tempo; História; Mundo.

ABSTRACT: In this technical note, I analyze the meanings, ambiguities and equivocities of saeculum in Confessions, XI, and The city of God, XIII, i; XV, i and XXI, to better understand the Augustinian conceptions of "eternity", "time", "universal history", "cosmic time", "historical time" and "world".

KEYWORDS: Saeculum; Eternity; Time; History; World.

Nesta nota técnica, analisarei as ocorrências de saeculum nas Confissões e em A cidade de Deus, com o propósito de proporcionar algum aporte teórico para a investigação em Agostinho de suas concepções de "eternidade", "tempo", "história universal", "tempo cósmico", "tempo histórico" e "mundo", as quais aparecem por vezes sob a rubrica de saeculum, nem sempre com uma clara univocidade. Com efeito, saeculum em Agostinho guarda notáveis equivocidades e ambiguidades, ademais exigindo por parte do intérprete dimensão de problemas filosóficos e teológicos complexos para decidir como ler saeculum em seus diferentes registros. Assim, o presente levantamento delimitou estrategicamente algumas ocorrências de saeculum em momentos-chave das obras e dos livros em que o intérprete encontra maior desenvolvimento da meditação agostiniana sobre a eternidade, a temporalidade e a história. Com mais precisão, apreciaremos a seguir

\footnotetext{
${ }^{1}$ Doutor em filosofia pela Universidade de São Paulo (USP) e professor na Pontifícia Universidade Católica de São Paulo (PUC-SP). E-mail: lmarcosfilho@gmail.com
} 
as ocorrências de saeculum em Confissões, XI, e A cidade de Deus, XIII, i; XV, i e XXI (entre as mais de duzentas incidências nesta obra).

No livro XI das Confissões (doravante Conf.), há somente seis ocorrências, o que é surpreendente em se tratando de um livro concentrado no problema da eternidade e do tempo a partir de exegese do primeiro versículo do Gênesis ("No princípio, criou Deus o céu e a terra"). As ocorrências parecem mobilizar sentidos precisos em:

Conf., XI, i, 12: Uma única ocorrência de saeculum por meio da citação do Salmo 117, 1: "[...] quoniam in saeculum misericordia tua". Vários tradutores entenderam saeculum aí como sinônimo de "eternidade", talvez supondo que o sentido seria o de saecula saeculorum. A tradução de Antonio Pereira de Figueiredo, direto da Vulgata "moderna" e bastante literal em relação ao latim (várias vezes coincidentes com a Vetus Latina ou a "Bíblia" de Agostinho, embora não aqui), traduz "porque a sua misericórdia se estende a todos os séculos". A Bíblia de Jerusalém, que traduz os Salmos direto do hebraico, ao qual Agostinho não tinha acesso, apresenta como "porque o seu amor é para sempre". Assim, tudo indica que na "Bíblia" de Agostinho o sentido era mesmo de eternidade, neste caso entendido por ele como perenidade e não como atemporalidade, conforme é explicitado o significado do redobro saecula saeculorum em A cidade de Deus, XXI, xxiii (cf. infra). Não obstante pareça estranho saeculum sem redobro, como citado aqui por Agostinho, guardar significado de eternidade ou perenidade, todavia parece não haver dúvidas de que este é o seu sentido, pois o mencionado trecho do $\mathrm{S} 1$ 117, 1, é uma anáfora presente nos quatro primeiros versículos deste Sl e provavelmente conhecidíssimo na época de Agostinho por qualquer catecúmeno.

Conf., XI, xiii, 15: Das seis ocorrências de saeculum no livro XI, metade, ou seja, três estão aqui neste parágrafo 15 , todas com o mesmo sentido, aparentemente. $O$ contexto é de refutação da absurda pressuposição de que haveria tempo antes do tempo por parte daqueles que ímpia e irracionalmente questionam o que fazia Deus antes de criar e por que Ele demorou tantos saecula para criar o mundo. O sentido nas três ocorrências

\footnotetext{
${ }^{2}$ As citações de Agostinho seguirão esse padrão, que, no caso, quer dizer livro XI, capítulo i, parágrafo I, das Conf.. Na ausência de menção, todas as traduções são de responsabilidade minha, a partir da edição do Corpus Christianorum.
} 
parece ser de temporalidade, não necessariamente histórica, e de tempos múltiplos de cem anos.

Conf., XI, xxviii, 38: Uma única ocorrência com sentido de "história universal", no contexto de exame da interfixação no espírito entre passado, presente e futuro na experiência de cantar uma canção (ou mesmo na recitação de cada uma de suas partes, a saber, palavras e sílabas), a qual é apresentada em analogia com a história biográfica de alguém ("tota vita hominis"), "cujas partes são todas as ações de um homem" (“cuius partes sunt omnes actiones hominis"), a qual, por sua vez, é análoga "ao século/história inteira dos 'filhos dos homens', cujas partes são todas as vidas dos homens" ("toto saeculo 'filiorum hominum', cuius partes sunt omnes vitae hominum").

Conf., XI, xxxi, 41: Uma única e última ocorrência no livro XI, com sentido de temporalidade, em continuidade e desdobramento da investigação da analogia entre o modo de conhecer divino, do ponto de vista totalizante da eternidade, e o modo de conhecer humano, do ponto de vista do tempo (como distentio, extentio e intentio). Para tanto, o conhecimento humano da totalidade de uma canção é disposto novamente como exemplo, mas agora em analogia ao que poderia ser a compreensão divina da totalidade de todos os tempos ou, a pensar se é o caso, da história universal. Saeculum aparece no plural em referência aos "séculos que restam" ("reliquum saeculorum"), que seriam conhecidos por Deus em semelhança e dessemelhança ao modo como um ser humano no ato de cantar conhece, durante a canção, "o quanto resta [dela] até o fim" ("quantum restet ad finem"). A pensar se se trata da "história universal", porque talvez se deva mobilizar aqui a distinção proposta por Marrou entre "tempo histórico" e "tempo cósmico": o "tempo histórico, o tempo segundo a Queda [...] é [...] apenas um aspecto da temporalidade [...]. É preciso conceber o que poderíamos chamar de um tempo cósmico, o tempo no qual se desdobra a obra da Criação divina"3.

Em $A$ cidade de Deus (doravante, DCD), entre as mais de duzentas ocorrências, na primeira parte (livros I a X), há somente quinze incidências, já na segunda parte (livros

\footnotetext{
3 “[...] temps historique, le temps d'après la Chute [...] n'est [...] qu'un aspect de la temporalité [...]. Il faille concevoir ce qu'on pourrait appeler un temps cosmique, le temps dans lequel se déploie l'oevre de la Création divine". MARROU, 1950, p. 65-66.
} 
XI e XXII), há todas as restantes. Abordarei aqui as ocorrências em somente três livros: XIII, XV e XXI, em que as ocorrências parecem estratégicas para a elucidação de multiplicidade de sentidos no interior da narração agostiniana e exercício de inteligência a partir da revelação de uma história universal.

$D C D$, XIII, i: Em todo livro XIII, há somente esta ocorrência: "Desembaraçadas as dificílimas questões sobre a origem de nosso século e sobre o início do gênero humano..." ("Expeditis de nostri saeculi exortu et de initio generis humani difficillimis quaestionibus..."). O sentido, diferente de todos aqueles de Conf., XI, parece ser antes topológico (ainda que não necessariamente espacial) do que temporal, como "mundo". Markus (1970) examina vários sentidos topológicos de saeculum, entre os quais se destaca o espaço histórico em que as duas cidades estão permixtae, que, todavia, não parece ser o presente aqui em XIII, i, mas vale dizer que a obra de Markus ainda é um dos comentários mais denso e incontornável na literatura crítica sobre saeculum na obra agostiniana e na Antiguidade Tardia, com a virtude de problematizá-lo no interior de uma história das ideias.

$D C D, \mathrm{XV}$ : Encontram-se dezenove ocorrências de saeculum (desconsiderando aquelas nos títulos dos capítulos adicionados por copistas). Aqui, concentro-me em XV, i, 1, em que Agostinho apresenta com todas as letras saeculum como sinônimo de história universal: “Afinal, a totalidade do tempo ou século, em que há sucessão e desaparição de morrentes e nascentes, é o decurso/percurso/desenvolvimento destas duas cidades, de que trataremos..." ("Hoc enim universum tempus sive saeculum, in quo cedunt morientes succeduntque nascentes, istarum duarum civitatum, de quibus disputamus, excursus est...”). Neste caso, se procede a distinção mencionada anteriormente entre "tempo histórico" e "tempo cósmico" proposta por Marrou, saeculum guarda sentido de "tempo histórico" (após a queda ou fratura entre homem e natureza e anterior ao fim dos tempos) e não de "tempo cósmico" (um tempo ordenado ou cosmológico sem contradições reais ${ }^{4}$ ).

$D C D, \mathrm{XXI}$ : Este livro realiza primordialmente exegese de Apocalipse para buscar a inteligência da revelação do suplício eterno ou da segunda morte dos cidadãos terrenos.

\footnotetext{
${ }^{4}$ Para um aprofundamento sobre os traços constitutivamente contraditórios da condição humana ou sobre fundação do "tempo histórico" em inadequação com um “tempo cósmico”, cf. SILVA FILHO, 2020.
} 
Das vinte e três ocorrências de saeculum, os três sentidos mais frequentes são como: (i) futurum saeculum, (ii) saecula saeculorum e (iii) hoc saeculum:

(i) Futurum saeculum aparece, por exemplo, em DCD, XXI, v, 2 e xiii. Em XXI, $\mathrm{xv}$, há a ocorrência também de novum saeculum, provavelmente com o mesmo significado de futurum saeculum, a saber, como "futuro mundo" e "novo mundo" em referência à esperança cristã num "mundo futuro", em que os seres humanos salvos viverão em paz e felicidade plenas após a ressurreição dos mortos, algo como um novo paraíso, que pode, não obstante, conter ainda um sentido de temporalidade, se a hipótese de Marrou de um "tempo cósmico" procede e se se admite que a alma da criatura racional é constitutivamente temporal.

(ii) Saecula saeculorum aparece em geral por meio de citações de Apocalipse, por exemplo, em $D C D$, XXI, xxiii; xxiv, 4, 5; xxvi, 3. Em XXI, xxiii, Agostinho diz com todas as letras que saecula saeculorum significa perenidade, perpetuidade, temporalidade sem fim, para esclarecer o sentido terrível de pena ou suplício ou morte eternas: “está escrito no Apocalipse: 'o Diabo, que os seduzia, foi lançado no lago de fogo e de enxofre, aonde também foram a besta e o falso profeta, onde serão atormentados dia e noite pelos séculos dos séculos' (Ap. 20, 9-10). O que lá foi chamado de 'eterno', aqui é chamado de 'séculos dos séculos', com que a Escritura não costuma significar senão o que não tem fim no tempo" (“scriptum est in Apocalypsi: 'Diabolus, qui seducebat eos, missus est in stagnum ignis et sulphuris, quo et bestia et pseudopropheta; et cruciabuntur die et nocte in saecula saeculorum' [Ap. 20, 9-10]. Quod ibi dictum est 'aeternum', hic dictum est 'in saecula saeculorum', quibus verbis nihil Scriptura divina significare consuevit, nisi quod finem non habet temporis").

(iii) hoc saeculum guarda o sentido de "este mundo", talvez reunindo significado tanto topológico, quanto temporal, por exemplo, em $D C D$, XXI, xxiv, 2; xxvi, 2 , em clara referência ao lugar em que os seres humanos se encontram em condição pecaminosa, mas também de lugar em que a graça e a presença do absoluto revelam-se. Assim, hoc saeculum guarda significado de dupla 
valência esclarecido mais uma vez pelo trabalho de Marrou (1950), que propõe concepção ambivalente do tempo histórico.

Em suma, pensar sobre os significados, equivocidades e ambiguidades de saeculum na obra agostiniana é expediente estratégico para melhor compreensão de alguns de seus temas e problemas mais elevados e originais: a eternidade, o tempo e a história. Para destacar um ponto em que a reflexão sobre a teologia e/ou filosofia da história agostiniana talvez ainda não tenha conferido a devida atenção, sublinho mais uma vez que "tempo" e "história" não guardam necessária sinonímia, pois é preciso discernir um "tempo cósmico", em que a racionalidade com que Deus criou o mundo é efetiva, e um "tempo histórico", fundado pela instituição humana de uma contradição original. No entanto, ambas as temporalidades aparecem sob a rubrica de saeculum, que com a adição também de seus significados de "eternidade" e de "mundo", nos contextos de exegese e meditação sobre o "lugar" e a "situação" do homem, pode conduzir-nos a uma polissemia filosoficamente mais profusa do que a equivocidade e a ambiguidade, porquanto reveladora de uma inadequação essencial entre ser, pensar e dizer constitutiva do "homem que anda em círculos carregando sua mortalidade" ou daqueles que "preferem andar em curto-circuito a seguir o caminho verdadeiro e reto" ${ }^{\text {. }}$

\section{Referências}

AUGUSTINUS. Confessiones. Corpus Christianorum Series Latina XXVII. Turnhout: Brepols, 1990.

AUGUSTINUS. De civitate dei (Libri I-X). Corpus Christianorum Series Latina XLVII. Turnhout: Brepols, 1955.

AUGUSTINUS. De civitate dei (Libri XI-XXII). Corpus Christianorum Series Latina XLVIII. Turnhout: Brepols, 1955.

AUGUSTINUS. Confissões. Trad. Lorenzo Mammì. São Paulo: Penguim Companhia das Letras, 2017.

MARKUS, R. A. Saeculum: History and Society in the Theology of St Augustine. New York: Cambridge University Press, 1970.

\footnotetext{
5 “[...] homo circumferens mortalitatem suam”. Conf., I, i, 1; 2017, p. 33 (tradução de Lorenzo Mammì).

6 “"...] in circuitu falso ambulare quam vero et recto itinere malint”. DCD., XII, Xvii, 2.
} 
MARROU, H-I. L'ambivalence du temps de l'histoire chez saint Augustin. MontréalParis: Vrin, 1950.

SILVA FILHO, L. M. DA. "Ontologia, linguagem e história em Agostinho: contradição e sexualidade n'A cidade de Deus". Dissertatio, Pelotas, volume suplementar 10, p. 243270, 2020, ISSN 1983-8891. Disponível em: https://periodicos.ufpel.edu.br/ojs2/index.php/dissertatio/article/view/20221. Acesso em 30 maio 2021, doi: 10.15210/DISSERTATIO.V0I0.20221. 